\title{
Os desafios da institucionalização do ensino superior na modalidade a distância: a visão dos gestores de uma universidade federal
}

\author{
João Paulo Rodrigues do Nascimento ${ }^{a}$ \\ Maria das Graças Vieira ${ }^{b}$
}

\section{Resumo}

O presente estudo apresenta as especificidades da $\mathrm{EaD}$ que se constituem em desafios para que essa modalidade de ensino se institucionalize nas Instituições de Ensino Superior. Realizou-se um levantamento dos gestores acadêmicos associados aos cursos de graduação em oferta na UFRN, traçando um perfil destes por meio da identificação dos cargos que exercem, unidades de lotação e tempo de serviço. O presente estudo assume uma natureza qualitativa, por meio de pesquisa participante, considerando tratar-se de amostra não probabilística intencional. Os resultados apontam que o processo de institucionalização ainda se encontra num estágio embrionário, embora se reconheçam os esforços dos gestores acadêmicos em compreender a importância da modalidade a distância no momento atual, com a inserção das tecnologias de informação e comunicação.

Palavras-chave: Educação a Distância. Ensino Superior. Institucionalização.

\section{Introdução}

A Educação a Distância (EaD) constitui, nos dias de hoje, uma realidade na qual as Instituições Federais de Ensino Superior estão inseridas. Com o desenvolvimento e aprimoramento de novas Tecnologias de Informação e Comunicação (TIC), é possível estabelecer uma interação efetiva entre os sujeitos do processo de educação formativa, além de promover a disseminação de informações e, consequentemente, a construção coletiva do aprendizado por meio da mediação tecnológica.

\footnotetext{
a Universidade Federal de Pernambuco - UFPE. Recife, Pernambuco, Brasil.

b Universidade Federal da Paraíba - UFPB. João Pessoa, Paraíba, Brasil. 
Nos últimos anos, os gestores das Instituições de Ensino Superior (IES) engendram esforços para consolidar as ações de $\mathrm{EaD}$ nas respectivas instituições. De acordo com a presidência do fórum de coordenadores institucionais do programa Universidade Aberta do Brasil (UAB), em 2013, existem 103 instituições que estão habilitadas para a oferta de cursos superiores na modalidade a distância. Contudo, observa-se a existência de entraves que dificultam e/ou desafiam a inserção da EaD na cultura organizacional das IES.

As abordagens sobre o tema da institucionalização da Educação a Distância tornam-se relevantes na atualidade, em virtude da necessidade de apresentar subsídios que fomentem as discussões que, por consequência, viabilizem a tomada de decisões sobre a inserção da modalidade a distância como uma alternativa institucional de promoção do processo de ensino-aprendizagem.

É conveniente destacar ainda que, segundo a Capes, as pesquisas em EaD que abrangem a institucionalização representam aproximadamente $2 \%$ do universo das pesquisas dentro desse eixo, o que legitima a relevância deste estudo. Apesar de existir algumas produções voltadas ao tema, as abordagens consistem em tratar aspectos focais da institucionalização, não resultando em abordagens que permitam uma compreensão global sobre a temática. Nessa perspectiva, o presente estudo busca proporcionar uma visão generalista sobre a institucionalização da $\mathrm{EaD}$, partindo da percepção de sujeitos que são responsáveis pela tomada de decisões no cerne das instituições.

Por conseguinte, o estudo ora realizado não pretende esgotar as discussões sobre o tema, mas instigar reflexões dos leitores, em especial os gestores da IES, sobre a conjuntura atual da Educação a Distância e as possibilidades que essa modalidade de ensino proporciona para as instituições de Ensino Superior em acompanhar a dinâmica educacional, por meio da mediação tecnológica. Nas próximas páginas, o leitor encontrará informações que, indubitavelmente, o levará pensar a $\mathrm{EaD}$ sob uma visão crítica e holística.

\section{A teoria institucional e sua aplicabilidade na EaD: o estado da arte}

No contexto dos estudos organizacionais, uma das teorias que abordama adaptação das organizações frente às mudanças e transformações é a Teoria Institucional (TI). Esse doutrinamento procura explicar como as organizações surgem ou se tornam estáveis. Mais especificamente, investiga como práticas e padrões adquirem condições de valores e são legitimados nas estruturas sociais. 
A Teoria Institucional teve seu início com as investigações de Meyer e Rowan (1977) sobre institucionalismo, segundo as quais as organizações são levadas a incorporar as práticas e procedimentos definidos pelos conceitos predominantes no ambiente organizacional e que estejam institucionalizados na sociedade.

Assim, as estruturas formais de muitas organizações refletem os mitos de seu ambiente institucionalizado em vez das reais necessidades das atividades de trabalho. Nessa perspectiva, a escola do institucionalismo histórico foi concebida por nomes como Thorstein Veblen e Gunnar Myrdal com o escopo de reação contra a análise da vida política, em termos de grupos, bem como contra o estruturalismo-funcionalismo (GUERREIRO; PEREIRA; FREZATTI, 2006).

A abordagem teórica supramencionada identificou, em nível macro, a incorporação de processos e estruturas das organizações que operam dentro de um mesmo campo, conceituada como o isomorfismo institucional. A aplicação do conceito de isoformismo nas organizações é interpretada como forma de garantir a sobrevivência, ou permanência, por intermédio de legitimação das práticas pelos agentes que compõem as instituições (DIMAGGIO; POWELL, 1983). Soma-se a esse processo, em nível micro, a construção de normas compartilhadas pelos atores individuais por meio de diferentes variáveis que interagem entre si, se constituindo na base da legitimação das ações (ESMAN, 1972; ESMAN; BLAISE, 1966).

No pensamento de Eisenhardt (1988), a ideia chave por trás da institucionalização é que muitas ações organizacionais refletem uma maneira de fazer coisas que evolui ao longo do tempo e torna-se legitimada dentro de uma organização ou ambiente. Para Eisenhardt (1988), essa legitimidade faz com que coisas sejam feitas de uma certa maneira, pelo simples fato de haver se tornado o único modo aceitável de fazê-las.

Para Scott (1987), a sabedoria implícita na abordagem da Teoria Institucional é a de reconhecer, desde o início, que não existe uma, mas diversas variantes que combinam o "velho" institucionalismo, com ênfase no conflito de interesses, competitividade e influência social, e o "novo" institucionalismo, com seu foco na legitimidade e agrupamento de áreas organizacionais, resultando no comumente chamado "neoinstitucionalismo".

A Teoria Neoinstitucional, originada na época de 1970, por sua vez, surge quando alguns sociólogos contestaram a distinção tradicional entre a esfera do mundo social e as esferas influenciadas por um conjunto de práticas associadas à cultura. As críticas a essa corrente teórica estão limitadas quanto à análise dinâmica interna da mudança organizacional e, por consequência, omissa sobre o motivo pelo 
qual algumas organizações adotam uma mudança radical, enquanto outras não, apesar de experimentarem as mesmas pressões institucionais. No entanto, essa teoria contém compreensões e sugestões que, elaboradas, fornecem um modelo de mudança que liga o contexto organizacional e a dinâmica intraorganizacional.

Assim, as Teorias Institucional/Neoinstitucional não são normalmente vistas como uma teoria de mudança organizacional, mas, geralmente, são consideradas uma explicação da similaridade (isomorfismo) e estabilidade de arranjos organizacionais em uma dada população ou área de interesse organizacional (GREENWOOD; HININGS, 1996).

Para Tolbert e Zucker (1999), a institucionalização é uma tipificação de ações tornadas habituais por tipos específicos de atores. Nesse sentido, ações em hábito são referentes a comportamentos, e tais comportamentos são adotados por indivíduos ou grupos de atores dispostos a resolver conflitos.

Schutz (1962) explica que, quando o mínimo de esforço é desprendido para que esse ciclo funcione, decisões são tomadas e problemas são resolvidos. Futuros conflitos poderão seguir os mesmos procedimentos se os atores envolvidos adotarem os mesmos procedimentos, classificando e categorizando ações passadas. Zucker (1988) afirma que esse é um processo chave da institucionalização, pois ele marca o desprendimento do significado da ação para o indivíduo.

Na visão de vários estudiosos, independentementede quem desempenha a ação, a partir daquele momento, a ação organizacional é generalizada e dá-se o nome de objetificação, adquirida a partir da habitualização. Há ainda um terceiro aspecto denominado sedimentação, por meio do qual os novos membros desconhecem a origem das tipificações.

Em se tratando de organizações de ensino, as aplicações da teoria institucional estão evidentes na medida em que se observa o caráter "democrático" que predomina na própria estrutura, na qual os agentes costumam ser caracterizados com elevada massa crítica, que favorece uma práxis permanente sobre as ações que são desenvolvidas, considerando o contexto socioambiental e temporal, fazendo com que as ações se modifiquem constantemente para atender às novas exigências da dinâmica social.

Nessas circunstâncias, considerando que a Educação a Distância é um fenômeno emergente que se encontra em fase de discussão na esfera acadêmica, é necessário que haja uma compreensão de como incorporar práticas, procedimentos, ações, políticas e diretrizes que estejam em consonância com a evolução das práticas difundidas nas IES, levando-se em consideração a atual dinâmica da sociedade contemporânea. 


\subsection{0 contexto da Educação a Distância nas organizações de ensino}

As instituições públicas de Ensino Superior brasileiras possuem diferentes estruturas de gerenciamento das políticas e ações da $\mathrm{EaD}$ em sua estrutura interna, podendo o núcleo operacional do Programa Universidade Aberta do Brasil (UAB) estar inserido na administração central da instituição ou em uma das unidades acadêmicas. Desse modo, cada universidade tem seu processo de amadurecimento institucional no ensino, pesquisa e extensão na modalidade a distância.

Assim, é comum termos, no organograma dos estabelecimentos universitários, a estrutura de centro, núcleo operacional e secretaria de $\mathrm{EaD}$ ou a coordenação da EaD estar distribuída nas unidades acadêmicas ou pró-reitorias de graduação. Em regra, esses locais oferecem infraestrutura física, tecnológica e de pessoal aos departamentos que oferecem cursos a distância e a professores que trabalhem em suas disciplinas no ensino presencial com o uso de tecnologias da EaD (NOVAIS; FERNANDES, 2011).

É nessa realidade que as IES se deparam com desafios a serem superados, pois, se por um lado as Tecnologias de Informação e Comunicação (TIC) vêm promovendo um reencantamento ao processo, por outro, são relatadas dificuldades associadas ao seu uso e controvérsias quanto ao seu reconhecimento, fatores que demonstram que a EaD no Brasil ainda não é uma prática institucionalizada (ASSMAN, 2005).

Ao analisar os impactos da modalidade a distância de ensino no meio acadêmico, Belloni (2003, p. 15) comenta sobre as peculiaridades do contexto educacional enfocando que "[...] o campo da educação é extremamente complexo e altamente resistente à mudança". Essa afirmação encerra uma reflexão sobre o papel das universidades na contemporaneidade, pois a evolução do sistema educativo, como consequência do desenvolvimento da sociedade, resultante de uma adaptação inevitável das pressões exteriores do ambiente social, político e cultural do qual faz parte, leva seu ambiente interno a ter o domínio ampliado para fora dos limites físicos, redefinindo papéis, tendo em vista que o ensino é também processado aquém e além de limites dos muros.

As políticas públicas para a expansão e desenvolvimento da $\mathrm{EaD}$ como modalidade de educação já são realidade. O Ministério da Educação (MEC), por meio de sucessivas normatizações e do credenciamento e avaliação de cursos e instituições, tem iniciado o processo de institucionalizar a $\mathrm{EaD}$, o qual, conforme conceito do Dicionário Aurélio, pode ser entendido como "dar começo, estabelecer, fazer comum". 
Por sua vez, Silva (2009, p. 124) amplia esse conceito de institucionalização, focando-a como "processo de fixar a aprendizagem que ocorre em indivíduos e grupos dentro dos departamentos de uma organização, incluindo sistemas, estruturas, procedimentos e estratégias".

Entre as ações das IES que estão avançadas nos processos de institucionalização da $\mathrm{EaD}$, podemos citar as seguintes: inserção de uma política de EaD no Plano Desenvolvimento Institucional (PDI) e no Projeto Pedagógico Institucional; aprovação de regimento da modalidade para oferta de cursos de graduação; criação de uma diretoria específica para $\mathrm{EaD}$; formação e capacitação para seus professores e técnicos administrativos; oferta de cursos de extensão, editais para oferta de disciplinas e fomento para pesquisas, vagas de monitoria e utilização de plataforma virtual integrada com dados do sistema acadêmico.

Outra estratégia que tem resultado numa experiência significativa a ser considerada no sentido de integrar os cursos presenciais e a distância diz respeito à oferta de disciplinas a distância nos cursos presenciais.

A Portaria $\mathrm{n}^{\circ} 4.059$, do MEC, de 10 de dezembro de 2004, oferece a possibilidade de as instituições de Ensino Superior credenciadas modificarem o projeto pedagógico de seus cursos, de modo que poderão, em até $20 \%$ das disciplinas e componentes do seu currículo, utilizar método não presencial.

Acerca disso, a Portaria $\mathrm{n}^{\mathrm{o}} 4.059$ define o conceito de modalidade semipresencial como quaisquer atividades didáticas, módulos ou unidades de ensino-aprendizagem centrados na autoaprendizagem e com a mediação de recursos didáticos organizados em diferentes suportes de informação que utilizem tecnologias de comunicação remota.

Por outro lado, nas IES ainda existem resistências em aceitar que a EaD possa ser realizada com o mesmo nível de qualidade que a educação presencial. Alguns, por medo da inovação e da mudança de papéis dos agentes educacionais; outros, por preconceito ou por acreditar que a Educação a Distância é um caminho mais fácil para obtenção do diploma.

A legislação que trata da Educação a Distância se tornou bastante ampla nos últimos anos no Brasil. Em relação ao sistema Universidade Aberta do Brasil (UAB), não é diferente: há diversas espécies normativas e/ou diplomas legais que regulam e ajustam o sistema $\mathrm{UAB}$, que obteve uma adesão exponencial pelas IES, com o objetivo de aumento em suas respectivas matrizes orçamentárias e respectivos investimentos. Justifica-se a necessidade de um elevado número de resoluções e 
portarias como uma forma de evitar distorções e atender as demandas dos gestores, como Centro de Aperfeiçoamento de Pessoal de Nível Superior (Capes), Fundo Nacional de Desenvolvimento da Educação (FNDE) e as IES (COSTA, 2007).

A oferta de cursos a distância tem sido um meio para o recebimento de recursos financeiros complementares nas universidades públicas, mediante pagamento de bolsas e subsídios, que tem custeado a contratação de pessoal, equipamentos e material de consumo para esses cursos. Nesse sentido, o desafio para as universidades tem se colocado na forma de compartilhar as novas TIC nas modalidades presencial e a distância, assim como integrar a gestão pedagógica e acadêmico-administrativa desses cursos.

Por fim, compreende-se que os indivíduos responsáveis pela execução de tarefas e procedimentos personificam e validam os principais modelos funcionais de operação necessários para a adequação das entidades às demandas sociais, adicionando complexidade à situação, pois essas interações internas, juntamente com os enlaces externos que levam as ações isomórficas e as conduzem a um processo de homogeneização (DIMAGGIO; POWELL, 1983), nem sempre são ações publicamente antagônicas.

\subsection{Programas governamentais}

Nos dias atuais, a Educação a Distância no Brasil é estruturada, induzida e fomentada por meio da Universidade Aberta do Brasil (UAB) que se configura em um programa estruturante direcionado a indução e fomento da educação superior na modalidade a distância. De acordo com a Diretoria de Educação a Distância,

[...] o Sistema UAB propicia a articulação, a interação e a efetivação de iniciativas que estimulam a parceria dos três níveis governamentais [...] com as universidades públicas e demais organizações interessadas, enquanto viabiliza mecanismos alternativos para o fomento, a implantação e a execução de cursos de graduação e pós-graduação de forma consorciada. Nessas condições, funciona como um eficaz instrumento para a universalização do acesso ao Ensino Superior e para a requalificação do professor em outras disciplinas, fortalecendo a escola no interior do Brasil, minimizando a concentração de oferta de cursos de graduação nos grandes centros urbanos e evitando o fluxo migratório para as grandes cidades (CAPES, 2013b).

Dessa maneira, o Governo Federal coloca em evidência como plataforma política a expansão da educação superior no país, conferindo-lhe certa prioridade no 
contexto dos financiamentos na esfera socioeducacional, visando à fixação do estudante em sua origem, reduzindo as necessidades de mobilidade para dar sequência aos estudos, o que antes se concentrava nos grandes centros urbanos.

Nesse princípio, o sistema Universidade Aberta do Brasil (UAB) foi instituído no ano de 2006, por meio do Decreto $\mathrm{n}^{\circ} 5.800$ (Brasil, 2006), com base nos modelos de universidades abertas existentes na Europa, com destaque para o modelo espanhol, e consiste em

[...] um sistema integrado por universidades públicas que oferece cursos de nível superior para camadas da população que têm dificuldade de acesso à formação universitária, por meio do uso da metodologia da educação a distância visando a expansão e a interiorização da oferta de cursos e programas de Ensino Superior. A partir de então, o Sistema UAB desenvolve o fomento da modalidade de educação a distância nas instituições públicas de Ensino Superior, bem como estimular pesquisas em metodologias inovadoras de Ensino Superior respaldadas em tecnologias de informação e comunicação (UAB, 2006).

Com base nessa conjuntura, o sistema UAB propicia a colaboração entre a União e os entes federativos e reforça a criação de centros de formação permanentes por meio dos polos de apoio presencial em localidades estratégicas, priorizando a formação de professores e gestores públicos, além de expandir a educação superior por meio da democratização da oferta de cursos em áreas estratégicas do conhecimento numa perspectiva regionalizada, culminando no fomento da institucionalização da modalidade (FERREIRA; MILL, 2013).

De acordo com dados extraídos da página eletrônica do sistema UAB (2006), o referido programa sustenta-se em cinco eixos fundamentais:

- Expansão pública da educação superior, considerando os processos de democratização e acesso.

- Aperfeiçoamento dos processos de gestão das instituições de Ensino Superior, possibilitando sua expansão em consonância com as propostas educacionais dos estados e municípios.

- Avaliação da educação superior a distância tendo por base os processos de flexibilização e regulação implantados pelo MEC.

- Estímulo à investigação em educação superior a distância no País. 
- Financiamento dos processos de implantação, execução e formação de recursos humanos em educação superior a distância.

Segundo informações constantes do Sistema de Informações do Programa Universidade Aberta do Brasil (SISUAB), em 2013, a CAPES contabiliza 103 instituições integrantes no Sistema UAB, entre universidades federais, universidades estaduais e Institutos Federais de Educação, Ciência e Tecnologia, atuando em 650 polos de apoio presencial espalhados em todo o país com 429.883 alunos ingressantes e 240.069 em curso. No que tange aos investimentos, foram contabilizados um aporte de $\mathrm{R} \$ 2.278 .928 .331,00$ desde a concepção do programa até agosto de 2013, de acordo com a DED-Capes.

Dentro do Programa UAB, existem dois planos que são desdobramento dos eixos de formação definidos entre as finalidades da Universidade Aberta do Brasil: o Plano Nacional de Formação em Administração Pública (PNAP) e o Plano Nacional de Formação de Professores da Educação Básica (PARFOR).

Conforme dados disponibilizados pela Capes (2009), o PNAP é um plano derivado de um Projeto Piloto executado pelo Ministério da Educação em Articulação com os entes federados em 2005 que, na ocasião, operacionalizou a primeira oferta de um curso em Administração na modalidade a distância, com um projeto pedagógico curricular unificado nacionalmente, com o objetivo de preparar pessoas para assumir funções gerenciais, fruto das demandas apresentadas pelo fórum das estatais brasileiras e financiado com recursos do Banco do Brasil.

Com o êxito dessa experiência, o Projeto Piloto foi reformulado pela SEED-MEC e atualmente consiste num plano com o objetivo de ofertar cursos superiores de graduação e pós-graduação com o escopo de formar indivíduos capazes de exercer atividades gerenciais especialmente voltadas a organismos mantidos pela rede pública em qualquer esfera dos entes federados.

Nesse plano, estão contemplados o fomento dos cursos de graduação (bacharelado ou tecnólogo) em Administração Pública e cursos de pós-graduação stricto sensu em Gestão Pública, Gestão Municipal e Gestão em Saúde. Até agosto de 2013, segundo a DED-Capes, 98.362 matrículas eram contabilizadas em todo o país em cursos fomentados por este plano, correspondendo a 40,97\% das matrículas do sistema UAB (CAPES, 2009). 
Por sua vez, o PARFOR, consoante às informações da Capes (2012), consiste em outro plano integrante do sistema UAB com o objetivo de fomentar a formação de professores para atuação na Educação Básica, em especial em áreas de conhecimento que possuem carência de profissionais habilitados na forma da legislação vigente. Trata-se de um plano

[...] implantado pela CAPES, em regime de colaboração com as Secretarias de Educação dos Estados, do Distrito Federal e dos Municípios e com as Instituições de Ensino Superior (IES), para oferta de cursos na modalidade a distância, no âmbito do Sistema Universidade Aberta do Brasil, para professores ou profissionais em exercício nas redes públicas de educação (CAPES, 2012).

Conforme informações extraídas do portal da Capes (2012), os tipos de cursos oferecidos são:

Primeira licenciatura - para docentes em exercício na rede pública da educação básica que não tenham formação superior.

Segunda licenciatura - para os docentes que possuem formação em licenciatura, mas atuam em área distinta desta formação, e Formação pedagógica - para docentes graduados e não licenciados que se encontram em exercício na rede pública da educação básica.

A UAB, segundo dados da Diretoria de Educação a Distância da Capes (CAPES, 2012), concentra 49,5\% dos alunos ativos em cursos de licenciatura, o que representa 118.720 matrículas em cursos direcionados à formação de professores com a oferta de vagas não presenciais para o Plano Nacional de Formação de Professores da Educação (PARFOR), atendendo a demanda levantada pela análise das pré-inscrições realizadas na Plataforma Freire pelos professores brasileiros.

\subsection{0 futuro da EaD - institucionalização ou extinção?}

Em princípio, Ferreira e Mill (2013, p. 154) apresentam o conceito de institucionalização como um:

[...] processo mediante o qual um conjunto de normas de comportamento que orientam uma atividade social considerada importante, adquire regulamentação jurídica formal. Num sentido mais amplo, institucionalização refere-se a um processo de 
cristalização de procedimentos, comportamentos, quer tenham ou não importância social relevante.

Considerando esse conceito inicial, percebe-se que a Educação a Distância tem avançado de forma gradativa e muitas foram as experiências observadas. No cenário internacional, a EaD adquiriu, com o passar dos tempos, qualidade e credibilidade para a sua expansão.

No Brasil, a Educação a Distância, principalmente com relação ao Ensino Superior, ainda é vista com resistência e descrédito e é motivada pela forte concorrência com as instituições privadas de ensino. Ademais, por ser uma modalidade que irá atender à grande massa populacional, necessita passar por ajustes que deem condições de transitar de forma normal pela sociedade, de ser aceita como uma modalidade inovadora e democratizadora do ensino e da educação.

Nos últimos anos, os gestores das Instituições de Ensino Superior engendram esforços para consolidar as ações de EaD nas respectivas instituições. Em 2013, das 103 instituições habilitadas para a oferta de cursos superiores na modalidade a distância, 56 são universidades federais, 30 são universidades estaduais e 17 institutos federais (FERREIRA; MILL, 2013).

Contudo, observa-se a existência de entraves que dificultam e/ou desafiam a inserção da EaD na cultura organizacional das IES. Para Silva (2009, p. 113), "a cultura é resultado de uma visão compartilhada por um grupo e isso caracteriza a sua ênfase no nível coletivo da aprendizagem, o que permite a construção coletiva da realidade social".

Mediante essa comprovação, é essencial que se realize uma análise da cultura existente nas instituições de Ensino Superior, considerando elementos componentes de sua estrutura, valores difundidos, metas, objetivos, plano estratégico e dinâmica de tomada de decisões, tudo isso associando à influência dos fatores externos que norteiam as ações organizacionais.

A partir dessa análise dos elementos da cultura institucional, será possível identificar com mais precisão os desafios que implicam a efetivação do processo de institucionalização do fenômeno, como é o caso da EaD no Ensino Superior. Baseando-se nessas ideias, o censo da Educação a Distância de 2012, promovido pela Associação Brasileira de Educação a Distância (ABED), fez um levantamento junto a instituições públicas e privadas acerca dos desafios institucionais, traduzidas na Tabela 1. 
Tabela 1. Gestores acadêmicos da UFRN com interface em EaD agrupados por cargo/função.

\begin{tabular}{lccc}
\hline Cargo/Função do Gestor & $\begin{array}{c}\text { Quantidade } \\
\text { mapeada }\end{array}$ & $\begin{array}{c}\text { Participação } \\
\text { efetiva }\end{array}$ & $\%$ \\
\hline Dirigentes do órgão gestor de EaD & 6 & 1 & 16,67 \\
Diretores de centros acadêmicos & 7 & 7 & 100,00 \\
Chefes de departamento & 10 & 5 & 50,00 \\
Coordenadores de cursos de graduação/EaD & 10 & 7 & 70,00 \\
Total & 33 & 20 & 60,60 \\
\hline
\end{tabular}

UFRN: Universidade Federal do Rio Grande do Norte; EaD: Ensino a distância.

Fonte: Autoria própria (2014).

A partir dessas informações, constatou-se que a Educação a Distância ainda é caracterizada como um fenômeno pontual e emergente, que se encontra fadado a sucumbir caso não se adotem práticas que permitam a sua inserção efetiva e continua no âmbito das instituições. Nessa perspectiva, a Tabela 1 apresenta um diagnóstico em que se observa que os três principais obstáculos estão associados à evasão discente, os desafios organizacionais em se adaptar à modalidade e a resistência dos educadores em fazer uso da modalidade.

Portanto, os planos institucionais deverão contemplar formas de equalizar a estrutura organizacional para atender às expectativas de professores e estudantes que optam por usar a mediação do processo educacional pela EaD.

\section{Metodologia da pesquisa}

O presente estudo parte do pressuposto que existe uma problematização detectada a partir de observações preliminares sobre o fenômeno da institucionalização da Educação a Distância nas IES. Considerando o conhecimento empírico empregado por um dos pesquisadores, com base nas observações de sua trajetória profissional, o estudo desenvolvido se enquadra metodologicamente numa perspectiva dialética, na qual parte de inferências a partir da observação in loco e numa abordagem qualitativa das interpretações da revisão literária do tema em contraposição aos discursos empregados pelos participantes da pesquisa, mediante aplicação de entrevistas contemplando questões estruturadas com base em um roteiro previamente concebido, permeando cinco eixos que transversalizam as discussões em EaD.

Trata-se, sobretudo, de uma pesquisa de natureza aplicada, exploratória e não-probabilística, intencional. Na concepção de Richardson (1999, p. 161), "na prática é muito difícil uma amostra intencional seja representativa do universo 
[...]", o que explica a participação de 20 gestores acadêmicos de um universo de 33 gestores mapeados, escolhidos com base no critério quanto ao exercício de cargos de gestão e, consequentemente, tomam decisões em um determinado ambiente organizacional (no caso da universidade pública, vinculada à esfera federal) dentre chefes de departamentos, diretores de unidades acadêmicas e gestores ligados ao órgão institucional responsável pela gestão da EaD.

Para o alcance dos objetivos do estudo, quanto aos procedimentos técnicos, foi realizado inicialmente o mapeamento dos gestores acadêmicos, citados anteriormente, traçando um perfil desses a partir dos indicadores de sexo, formação acadêmica, tempo de exercício profissional na instituição e há quanto tempo exercem o atual cargo de gestão, a partir da consulta de relatórios junto ao departamento de administração de pessoal da IES e outros documentos institucionais, caracterizando dessa forma uma pesquisa documental. Esses procedimentos constituíram a $1^{\mathrm{a}}$ fase da pesquisa.

Em sequência, os gestores foram agrupados em dois segmentos conforme seus âmbitos de atuação administrativa: integrantes do órgão executivo de $\mathrm{EaD}$ (coordenação geral, coordenadores setoriais, assessorias especializadas) e gestores subvencionados às unidades acadêmicas (diretores de centro, chefes de departamentos e coordenadores de curso na modalidade a distância). A estratégia ora apresentada teve por objetivo transversal viabilizar a execução da pesquisa em sua $2^{\text {a }}$ fase, na qual o pesquisador interagiu diretamente com os participantes por meio de audiências (encontros agendados conforme disponibilidade dos participantes), aplicando uma entrevista direcionada a partir de um roteiro prévio, apresentando questões relacionadas ao pensamento do gestor sobre as políticas e ações de EaD adotadas pela IES, no caso a UFRN, trocando ideias e realizando inferências quanto aos aspectos que dificultam/desafiam a institucionalização dos procedimentos levando-se em consideração as especificidades da EaD. A Figura apresenta um esquema metodológico do estudo desenvolvido.

Avaliando a figura, percebe-se que se trata de uma pesquisa complexa, que envolveu duas fases bem definidas e exigiu um relativo esforço para sua concretização, na medida em que abrangeu um número significativo de sujeitos que abordaram várias dimensões sobre o tema investigado, sem perder de vista os eixos definidos no roteiro prévio elaborado pelo pesquisador.

É conveniente destacar que o áudio das sessões com os gestores foi gravado com o consentimento dos participantes para análise de seus discursos, a posteriori. Consoante a definição de Porto (2012), a análise do discurso é definida como 


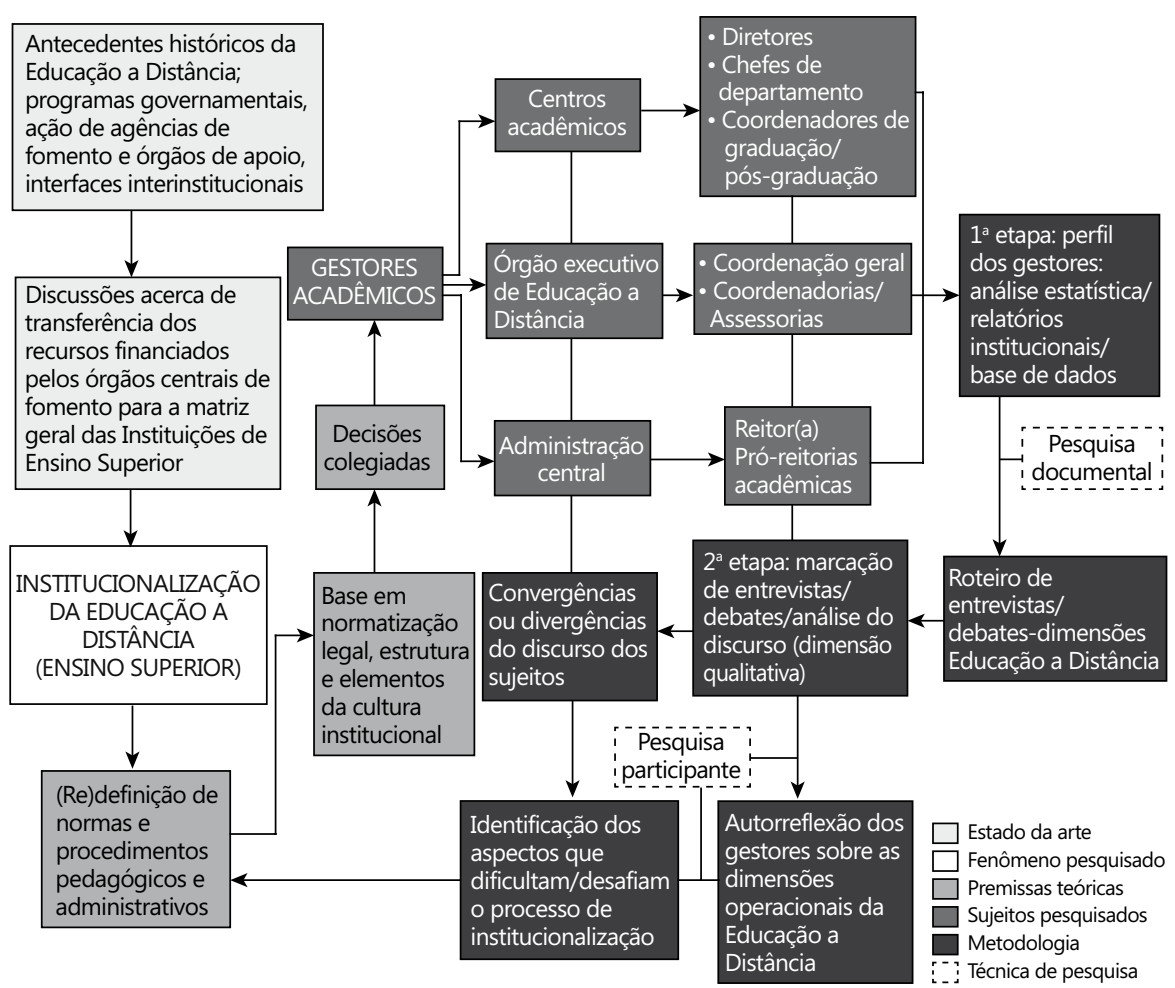

Fonte: Autoria própria (2014).

Figura. Esquema de pesquisa.

"uma prática da linguística no campo da Comunicação, e consiste em analisar a estrutura de um texto e a partir disto compreender as construções ideológicas presentes no mesmo". Nessa perspectiva, a pesquisa procurou investigar a existência ou não de um alinhamento no pensamento dos participantes no que tange aos eixos dimensionadores da institucionalização.

Para viabilizar e agilizar a análise do discurso dos sujeitos participantes, o pesquisador utilizou aplicativos/programas computacionais. Com base nessa compreensão construída, identificaram-se os entraves institucionais para a consolidação das práticas educacionais empregando a modalidade a distância, a partir da perspectiva crítica de Foucault (1996), que abrange "os meios de exclusão, limitação e apropriação do discurso. Também investiga como esses meios se formaram, a que necessidades vieram responder, como se modificaram durante o tempo, qual a limitação que realmente exerceram e em que medidas foram modificadas". 
A análise do discurso proposta por Foucault abrange os princípios da inversão (reconhecimento das fontes dos discursos); descontinuidade (os discursos podem se ignorar ou se excluir); especificidade (o discurso não se limita a ser um jogo de significações prévias) e exterioridade (propriedade do discurso capaz de produzir diversas possibilidades de interpretação). Aplicando-se esses princípios no presente estudo, a análise dos discursos dos gestores participantes foi realizada a partir dos temas que os próprios participantes se predispuseram a abordar, evidenciando-se as questões mais recorrentes em cada encontro realizado para a execução da pesquisa.

\section{Análise e discussão dos resultados}

A presente pesquisa foi realizada no âmbito da Universidade Federal do Rio Grande do Norte (UFRN), que é uma autarquia vinculada ao Ministério da Educação, mantida pelo Governo Federal. Sua estrutura envolve a Administração Central, sete pró-reitorias, duas secretarias, duas superintendências, oito centros acadêmicos e seis unidades acadêmicas especializadas, três escolas de ensino técnico e um colégio de aplicação. Soma-se ainda a estrutura os hospitais universitários, os museus e uma emissora de televisão educativa em canal aberto e uma rádio com frequência modulada.

A Administração Universitária é exercida pelos colegiados deliberativos e órgãos executivos. De acordo com o seu estatuto, a UFRN dispõe de quatro colegiados: Conselho Universitário (CONSUNI), Conselho dos Curadores (CONCURA), Conselho de Administração (CONSAD), Conselho de Ensino, Pesquisa e Extensão (CONSEPE).

\subsection{A visão dos gestores acadêmicos sobre a institucionalização da EaD: resultados e discussões}

Em princípio, para a realização do presente estudo, foi solicitada uma autorização formal junto à Administração Central da IES. A partir desse documento de autorização, foi aberto um processo administrativo, devidamente instruído, com a solicitação e versão impressa do anteprojeto de pesquisa acadêmica.

Após a devida tramitação, a dirigente máxima da instituição emitiu parecer favorável à execução da pesquisa. Desse modo, a presente pesquisa contou com a participação de 20 gestores acadêmicos da Universidade Federal do Rio Grande do Norte (UFRN), o que representa um percentual de $60,6 \%$ do universo mapeado, conforme discriminado na Tabela 1 .

Observando-se os dados expostos na Tabela 1, percebe-se que os gestores acadêmicos compreendem a importância da pesquisa para o universo acadêmico, 
uma vez que $60,6 \%$ destes participaram espontaneamente das sessões de entrevistas. É conveniente destacar a participação maciça dos diretores de centros acadêmicos, o que corrobora a tese de que os gestores de hierarquia mais elevada estão sensíveis às questões relacionadas com $\mathrm{EaD}$ e cientes de que a atuação deles pode impactar no trabalho desenvolvido na instituição.

No que diz respeito aos dirigentes vinculados ao órgão gestor de EaD na IES pesquisada, a explicação para a participação reduzida reside no fato de que a maioria deles não possui liberação pelas unidades de lotação (departamentos acadêmicos) para se dedicar exclusivamente às atividades de gestão inerentes ao órgão de EaD; fazendo com que atuem em regime de tempo parcial e em horários não coincidentes, o que inviabilizou a aplicação de uma entrevista conjunta ou mesmo as participações individuais.

A Tabela 2, por sua vez, apresenta os mesmos 33 sujeitos mapeados para participar da pesquisa, agrupados de acordo com suas unidades de gestão (centros ou unidades acadêmicas especializadas), bem como os respectivos índices de participação, independentemente dos cargos/funções exercidas. Com o escopo de preservar a identidade das unidades de gestão, convencionou-se, nesta pesquisa, a nomenclatura dos centros para Centro A, B, C, D, E, F e G.

Ponderando os dados apresentados na Tabela 2, ratificamos o interesse dos gestores em participar das sessões que foram realizadas com o intuito de expor suas considerações acerca da Educação a Distância sob a perspectiva das especificidades intrínsecas a cada unidade. À exceção do Centro $\mathrm{C}$ e do órgão gestor de $\mathrm{EaD}$, as demais unidades se fizeram representar com índices superiores a 50\% de participação.

A justificativa pela baixa participação do órgão gestor de $\mathrm{EaD}$ foi citada por ocasião da exposição dos dados da Tabela 2 , enquanto que os gestores do Centro $\mathrm{C}$ alegaram a incompatibilidade de tempo em função das diversas demandas prioritárias que são próprias à atividade docente para o momento em que a pesquisa foi aplicada.

Cabe destacar que as informações apresentadas foram coletadas a partir de um mapeamento dos gestores, tendo por base os cursos superiores de graduação na modalidade a distância ativos na instituição e tendo como referência o ano de 2014. A partir do levantamento dos cursos de graduação na modalidade a distância, identificaram-se os departamentos, os centros acadêmicos e as unidades superiores que são afetas e que, por conseguinte, lidam, de forma direta, com o alunado que ingressa na instituição por meio de processo seletivo específico para os cursos em EaD. 
Os dados que serviram de base para traçar o perfil dos gestores acadêmicos da IES pesquisada foram coletados a partir de consultas a diversas bases de dados confiáveis, como o Portal da Transparência do Governo Federal e portais institucionais, que trazem informações precisas acerca da data de ingresso na Universidade e do cargo/função que atualmente exercem os gestores e, a partir dessas informações, apresenta-se um conjunto de indicadores que proporciona uma noção de como a instituição é gerenciada.

\subsection{O perfil dos gestores acadêmicos da instituição federal}

Para efeitos de compreensão, concebe-se como gestor acadêmico a pessoa responsável por planejamento, orientação, controle e direção das atividades dentro da instituição que produz interface direta com o processo de ensino-aprendizagem. Sob essa ótica, excluem-se do universo de pesquisa gestores que, embora exerçam ações relevantes, não estão em contato direto com o processo formal de ensino-aprendizagem.

O perfil dos gestores acadêmicos traçado nesse estudo é apresentado sob a lógica da Tabela 2, uma vez que se trata de uma exposição de indicadores estatísticos que permitem uma compreensão sobre os sujeitos que integraram a pesquisa.

- Dirigentes do órgão institucional de EaD: encontram-se nesse grupo os coordenadores que exercem funções de gerenciamento, definidas na forma regimental, responsáveis pela operacionalização das ações que viabilizam pedagógica e administrativamente a educação, na modalidade a distância no âmbito da Universidade. Nesse segmento, estão mapeados seis gestores.

- Diretores de unidades acadêmicas: de acordo com a reforma universitária de 1968, as unidades acadêmicas que ofertam cursos dentro da mesma área de conhecimento e/ou áreas correlatas agrupam-se em centros, que detêm a responsabilidade de superintender as ações dos departamentos e cursos afetos. Nesse grupo, foram identificados e mapeados sete gestores de centros/unidades especializadas que abrigam departamentos/cursos que fazem uso da modalidade EaD.

- Chefes de departamento: de acordo com a estrutura organizacional, o departamento acadêmico constitui-se na menor unidade responsável pelas ações de ensino, pesquisa e extensão que a universidade se propõe a executar em sua missão. É nesse órgão que se estabelece a interface da administração com o corpo docente, determinando em planejamento as atividades em consonância às diretrizes estipuladas no plano de gestão universitária. Nesse grupo, foram mapeados 10 gestores oriundos dos departamentos que ofertam componentes curriculares na modalidade $\mathrm{EaD}$, em cursos superiores de graduação. 
- Coordenadores de cursos de graduação: é na coordenação do curso que se articula o processo de ensino junto aos departamentos acadêmicos e onde se realiza a interface com o alunado, desenvolvendo o acompanhamento acadêmico destes desde o ingresso na instituição até a conclusão do curso. Nesse segmento, reúnem-se 11 gestores que coordenam cursos de graduação na modalidade a distância em oferta na IES em estudo.

A partir da descrição dos perfis dos gestores pesquisados associando aos dados coletados, obtêm-se os seguintes resultados que podem ser vistos na Tabela 3.

Avaliando os dados apresentados na Tabela 3, percebe-se nitidamente a complexidade e a diversidade de gestores que a instituição possui. Cabe destacar, dentre os dados apresentados, que há predominância de homens no exercício dos cargos/funções de gestão acadêmica, sendo $60,6 \%$ do sexo masculino e os outros 39,4\% do sexo feminino (Gráfico 1). Caracteriza-se, então, como uma instituição plural e que não concentra os postos de comando considerando o sexo como fator determinante.

No que diz respeito ao grau acadêmico/titulação, por se tratar de uma IES comandada por docentes, 90,91\% dos gestores são doutores ou pós-doutores, o que permite afirmar que se trata de uma massa crítica com elevada formação (Gráfico 2).

No que tange ao tempo médio de serviço dos gestores, este foi calculado considerando-se a data de ingresso na instituição e a data de designação para o

Tabela 2. Unidades de Gestão da UFRN com representação na pesquisa.

\begin{tabular}{lccc}
\hline Agrupamento por Unidade de Gestão & $\begin{array}{c}\text { Quantidade } \\
\text { mapeada }\end{array}$ & $\begin{array}{c}\text { Participação } \\
\text { efetiva }\end{array}$ & $\%$ \\
\hline Centro A & 3 & 3 & 100,00 \\
Centro B & 5 & 4 & 80,00 \\
Centro C & 7 & 3 & 42,85 \\
Centro D & 4 & 3 & 75,00 \\
Centro E & 3 & 2 & 66,67 \\
Centro F & 4 & 2 & 50,00 \\
Centro G & 2 & 2 & 100,00 \\
Órgão gestor de EaD & 6 & 1 & 16,67 \\
Total & 33 & 20 & 60,60 \\
\hline
\end{tabular}

UFRN: Universidade Federal do Rio Grande do Norte; EaD: Ensino a distância.

Fonte: Autoria própria (2014). 


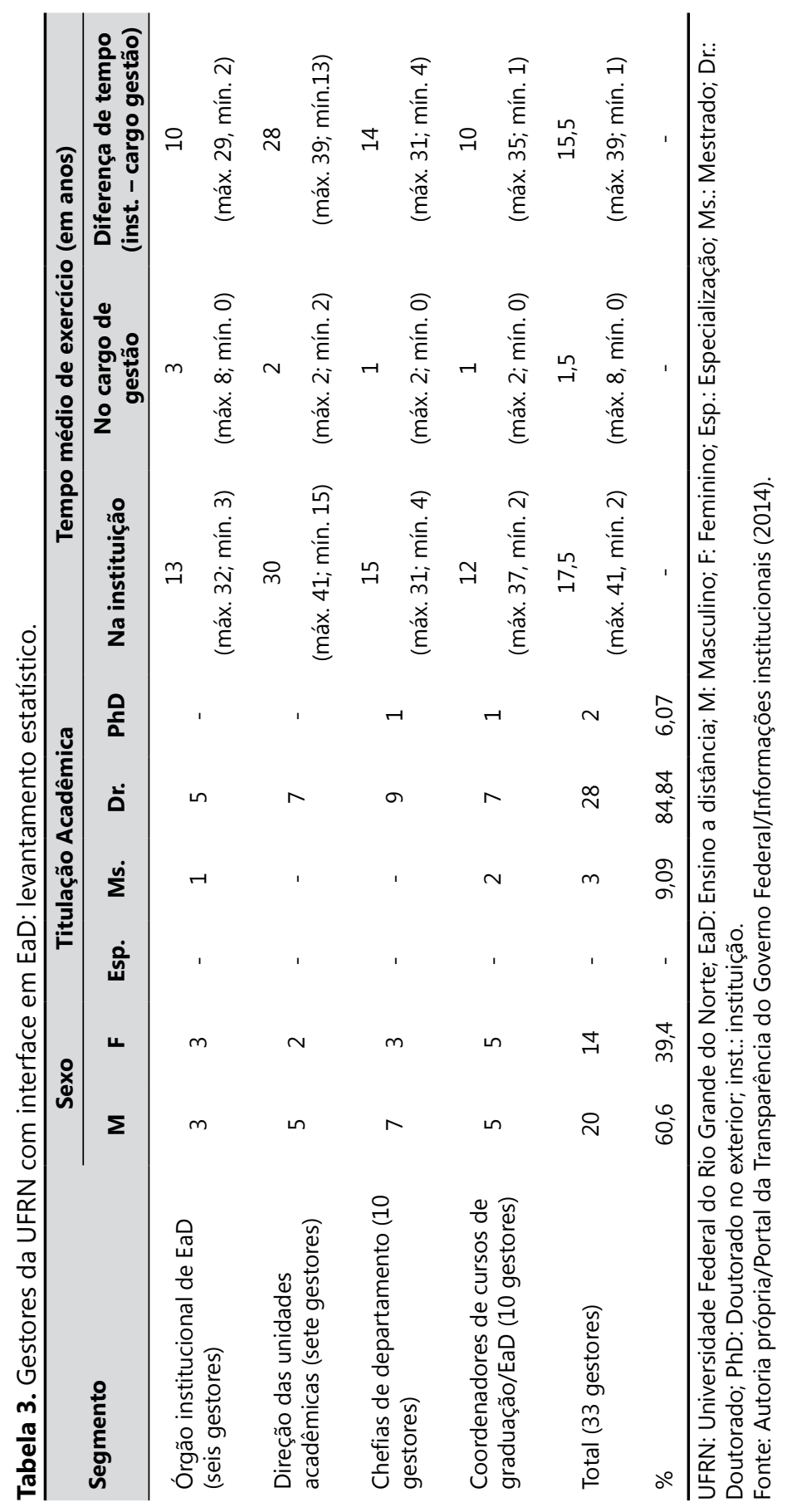


exercício do atual cargo de gestão e analisando-se as situações de cada gestor na data de 31 de maio de 2014 (data limite de aplicação da pesquisa). Obteve-se, assim, um comparativo entre o tempo de ingresso e o tempo que os gestores levaram para serem designados para exercer atividades de gestão no cargo/função atual.

Nesse sentido, cabe destacar que, geralmente, um gestor exerce vários cargos ao longo da carreira (principalmente tratando-se de gestores docentes), mas o que é relevante para este estudo é a atual condição dos gestores e suas respectivas interfaces com a Educação a Distância. Nessas condições, o Gráfico 3 apresenta

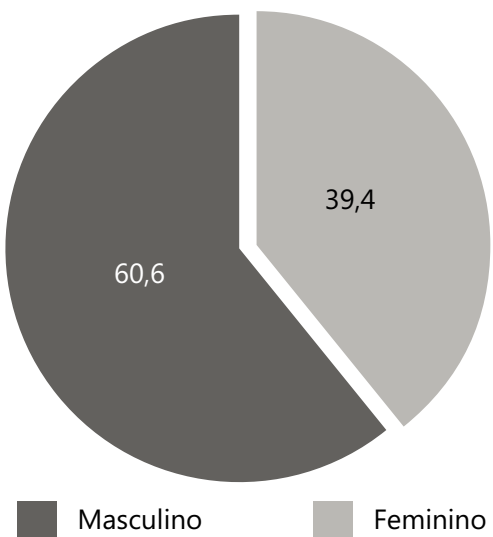

Fonte: Autoria própria/Dados da pesquisa (2014).

Gráfico 1. Divisão dos gestores acadêmicos por gênero (\%).

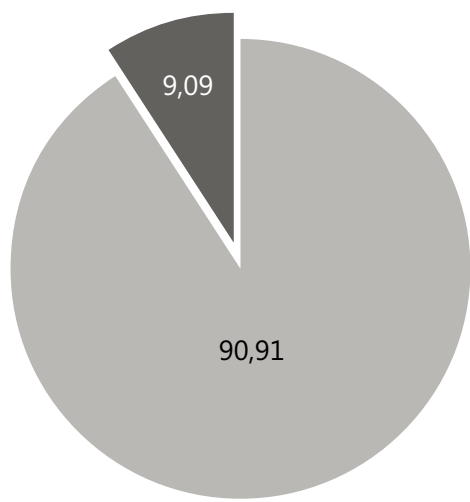

Doutorado/pós-doutorado

Fonte: Autoria própria/Dados da pesquisa (2014).

Gráfico 2. Divisão dos gestores acadêmicos por grau acadêmico (\%). 
uma comparação entre a média de tempo de serviço dos gestores acadêmicos por segmento e o tempo de exercício no atual cargo.

Observando-se o Gráfico 3, percebe-se que os gestores que exercem cargos de direção de centro apresentam tempo de serviço na instituição acima da média do universo dos gestores pesquisados, o que permite inferir, por um lado, que possuem competência/conhecimento para abordar sobre a cultura institucional e suas políticas de inserção de novos fenômenos. Por outro lado, percebem-se situações em que a atual gestão é recente, pelo tempo médio em exercício nos atuais cargos, na faixa de um ano e meio. Nesses casos, a característica é a de estarem se apropriando dos procedimentos inerentes às funções exercidas; embora valha enfatizar que, apesar do pouco tempo no atual cargo, não se invalida o fato de os gestores terem exercido outros cargos de gestão em momentos anteriores na carreira.

Resgatando os dados constantes da Tabela 3, na variável do tempo de exercício dos gestores, percebe-se a inserção propositada de informar a amplitude da amostra por segmento de gestão, uma vez que a média se caracteriza em uma medida de tendência central que, no caso, não necessariamente, reflete de forma

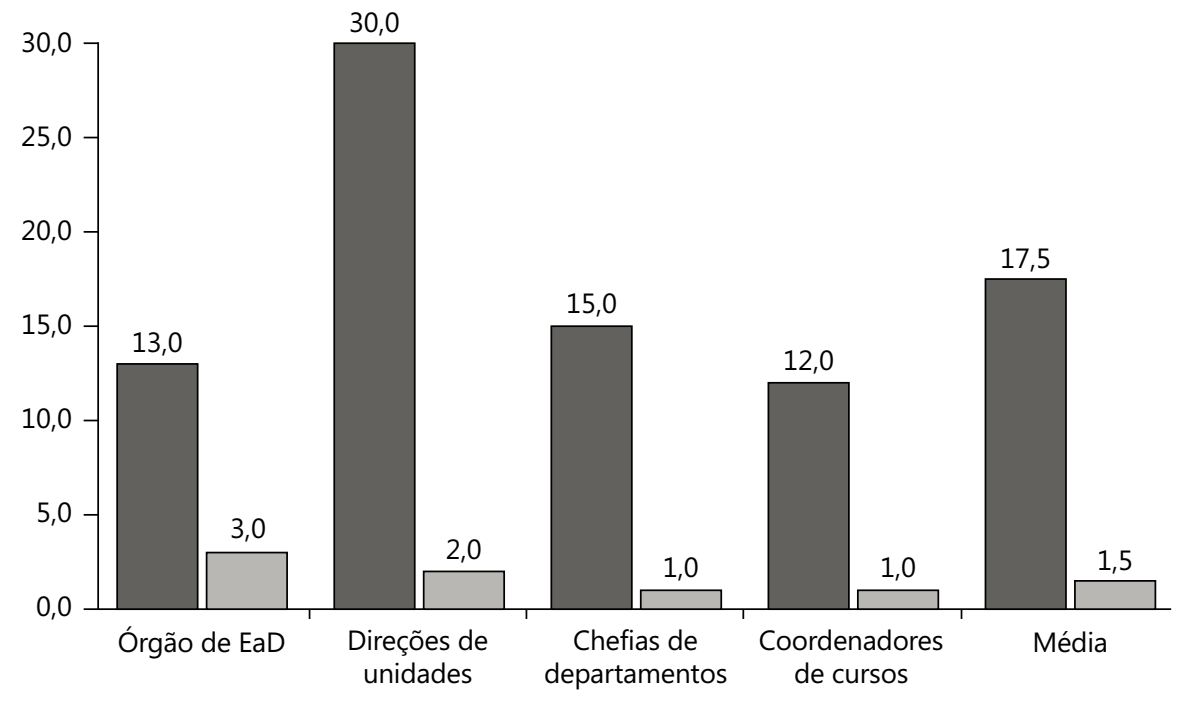

Tempo de instituição Fonte: Autoria própria (2014).

Gráfico 3. Comparativo entre o tempo médio de instituição e do atual cargo de gestão (em anos) 
precisa a realidade do fenômeno em estudo. Dessa forma, uma análise detalhada permite afirmar que os sujeitos participantes da pesquisa possuem características bastante heterogêneas, constatando-se uma diversidade de pensamentos e discursos personalizados sobre o tema da institucionalização da EaD.

\section{3 institucionalização da EaD a partir da análise do discurso dos gestores}

A segunda fase pesquisa foi efetivada mediante realização de encontros (audiências) com os gestores dentro da perspectiva da Tabela 2, agrupados na perspectiva da unidade de gestão, a partir das seguintes razões: o agrupamento por unidade gestora permitiu um diagnóstico mais preciso acerca dos aspectos que desafiam a consolidação da $\mathrm{EaD}$, levando-se em consideração a realidade de cada unidade, suas regras, sua cultura e seus princípios norteadores e ressaltando que cada uma delas possui relativa autonomia para definir suas diretrizes operacionais.

Ao todo, foram realizadas oito audiências no período compreendido entre os meses de abril e maio de 2014; das quais 20 sujeitos participaram, de um universo de 33 mapeados e qualificados na $1^{\text {a }}$ fase da pesquisa.

Já em relação ao roteiro da pesquisa com os gestores acadêmicos, seguindo audiências pré-agendadas, ele baseia-se em questões que foram divididas em cinco dimensões (ou eixos), para contemplar aspectos sobre o fenômeno da institucionalização.

Como se tratam de questões relacionadas com o campo da educação a distância, foram priorizadas as abordagens nas dimensões: aspectos organizacionais e logísticos, trabalho docente, recursos tecnológicos, formação discente e considerações gerais.

Em cada uma das dimensões foram formuladas questões direcionadas, previamente, para que cada gestor pudesse respondê-las, levando-se em consideração a natureza do seu cargo. Contudo, foi propiciado que os demais gestores fizessem colocações complementares, contribuindo para o enriquecimento das discussões realizadas em cada sessão.

No Quadro, expõe-se uma síntese do discurso dos participantes sobre as questões levantadas, em paralelo com a análise do pesquisador, seguindo as abordagens em cada uma das dimensões. Para a realização do procedimento, recorreu-se à transcrição do áudio registrado durante as sessões (com o auxílio da ferramenta computacional Express Scribe $^{\circledR}$ ) e do cruzamento das respostas, conforme as dimensões estabelecidas 


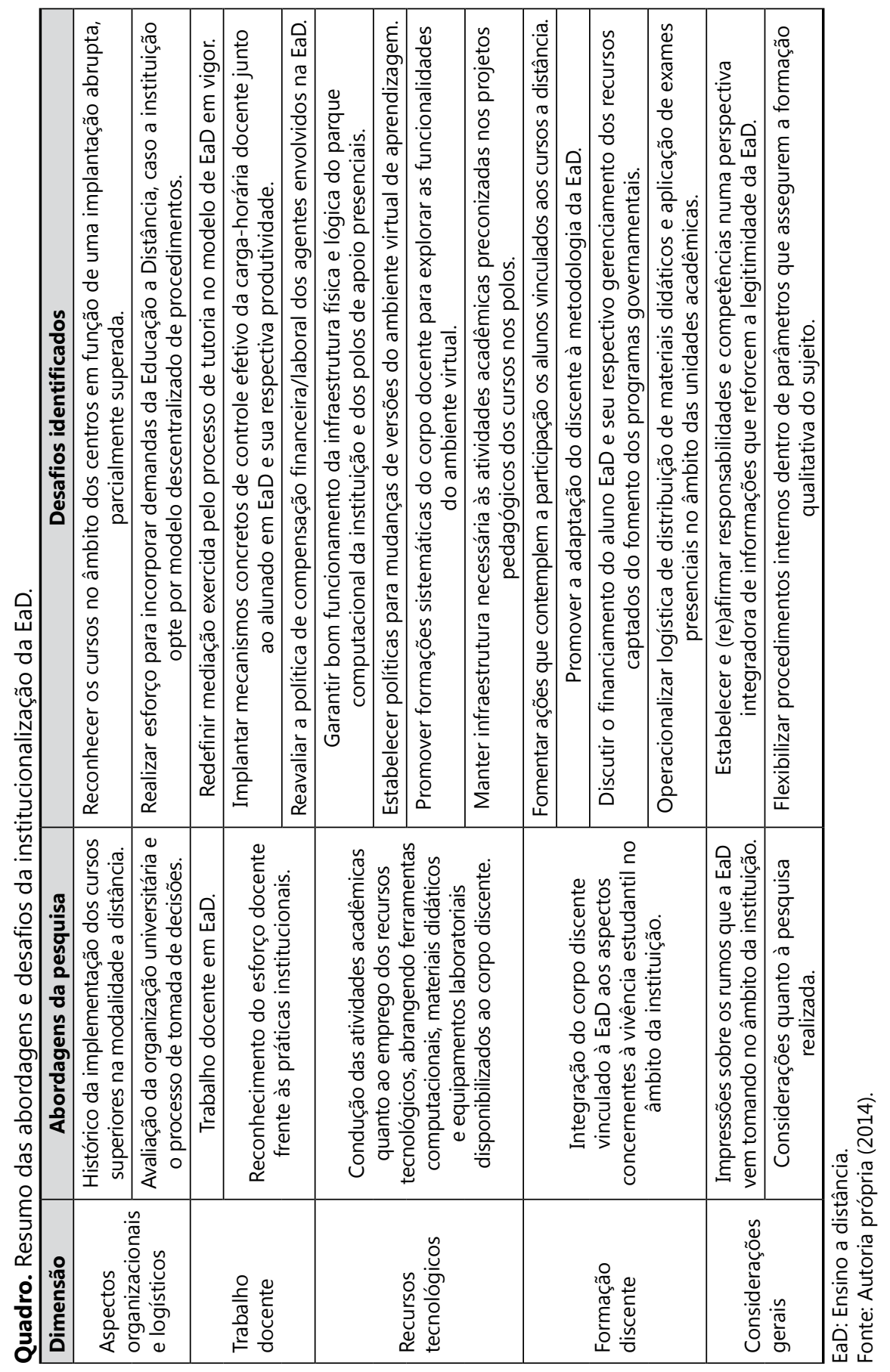


no roteiro. Convém registrar que a síntese não apresenta transcrições de falas dos participantes, visando assegurar o sigilo das identidades dos respondentes.

\section{Considerações finais}

A partir da aplicação da análise de discurso definida por Foucault (1996) como resposta à questão de pesquisa do estudo em pauta, acerca do entendimento dos gestores acadêmicos da UFRN, são fatores que desafiam a institucionalização da EaD na instituição pesquisada:

- A falta de um canal de diálogo permanente entre os gestores, com vistas ao compartilhamento de informações importantes e de espaço para debater as situações configuradas com vistas à tomada de decisões coletivas e uniformes.

- O estabelecimento de mecanismos que permitam ao gestor acompanhar efetivamente a produtividade e o trabalho docente em $\mathrm{EaD}$ de modo a promover o redimensionamento do trabalho destes no esforço acadêmico.

- O fortalecimento de ações de capacitação permanente em TIC para a comunidade acadêmica numa perspectiva focada nos sujeitos envolvidos, acompanhado de uma política de atualização de ambientes virtuais e sistemas que assegurem uma adaptação plena dos sujeitos envolvidos com a EaD.

- A inexistência de um redimensionamento quanto aos itens de fomento para a $\mathrm{EaD}$, de modo que o orçamento consignado pelos órgãos financiadores contemplem outras dimensões da vida acadêmica do estudante, não se limitando apenas ao ensino, garantindo sua permanência e investindo na sua formação global.

- Reconfiguração das competências dos agentes envolvidos com a EaD, em especial dos entes federados que coparticipam das políticas de oferta e demanda dos cursos superiores, com o objetivo de assegurar a infraestrutura necessária para a execução dos projetos pedagógicos curriculares desenvolvidos pelas IES.

- Transformação da modalidade a distância de ensino numa rotina institucional, independentemente da existência de programas governamentais que fomentem o uso de tecnologias de informação e comunicação.

Ademais, os gestores acadêmicos, apesar da consciência de seus papéis como agentes responsáveis pela tomada de decisão, devem estabelecer um diálogo efetivo entre todos aqueles que compõem a comunidade universitária, discutindo formas e estratégias para aperfeiçoar as práticas em Educação a Distância, redesenhando diretrizes e procedimentos operacionais, de modo a fortalecer o processo educacional numa perspectiva ampla, buscando meios para favorecer 
o estímulo dos profissionais que aderem à $\mathrm{EaD}$, remetendo, assim, às ideias de Dimaggio e Powell (1983) sobre institucionalização.

Em suma, é permitido inferir que os desafios para que a Educação a Distância se consolide nas instituições públicas de Ensino Superior, tomando por base a Universidade Federal do Rio Grande do Norte, concentram-se em três pontos fundamentais, quais sejam: esforço docente; fomento financeiro e papel da tutoria. Contudo, uma análise em outras IES adotando-se o modelo metodológico empregado no presente estudo proporcionaria uma visão mais abrangente de como está sendo conduzida a questão da institucionalização da Educação a Distância, enquanto modalidade de ensino devidamente reconhecida. 


\title{
Institutionalization the challenges of higher education in distance mode: the vision of managers of a federal university
}

\begin{abstract}
This study presents the specifics of de that constitute challenges for this type of education is institutionalized in higher education institutions. We conducted a survey of academic managers associated with undergraduate courses on offer in UFRN by establishing a profile of these through the identification of their roles, units of capacity and service time. This study takes a qualitative nature, through participatory research, considering that it was intentional non-probabilistic sample. The results indicate that the process of institutionalization is still in an embryonic stage, although they acknowledge the efforts of academic managers in understanding the importance of distance mode at the moment, with the inclusion of information and communication technologies.
\end{abstract}

Keywords: Distance education. Higher education. Institutionalization.

\section{Institucionalización los retos de la educación superior en modo distancia: la vision de los gerentes de una universidad federal}

\section{Resumen}

Este estudio presenta los detalles de de que constituyen retos para este tipo de educación está institucionalizada en instituciones de educación superior. Hemos llevado a cabo una encuesta de gerentes académicos asociados con los cursos de pregrado que se ofrecen en UFRN mediante el establecimiento de un perfil de estos a través de la identificación de sus funciones, unidades de capacidad y tiempo de servicio. este estudio tiene un carácter cualitativo, a través de la investigación participativa, teniendo en cuenta que fue intencional muestra no probabilística. Los resultados indican que el proceso de institucionalización se encuentra todavía en una fase embrionaria, aunque reconocen los esfuerzos de los responsables académicos en la comprensión de la importancia de la modalidad a distancia en el momento, con la inclusión de tecnologías de la información y de la comunicación.

Palabras clave: Educación a distancia. Educación superior. Institucionalización. 


\section{Referências}

ASSMAN, H. Redes digitais e metamorfose do aprender. Petrópolis: Vozes, 2005.

BELLONI, M. L. Educação a distância. 3. ed. Campinas: Autores Associados, 2003.

BRASIL. Decreto $\mathrm{n}^{0} 5.800$, de 9 de julho de 2006. Dispõe sobre o Sistema Universidade Aberta do Brasil- UAB. Diário Oficial da União, Brasília, DF, 9 jun. 2006.

. Ministério da Educação. Portaria $\mathrm{n}^{\circ} 4.059$, de 10 de dezembro de 2004. Diário Oficial da União, Brasília, DF, 13 dez. 2004. Seção 1, p. 34.

CAPES-Coordenação de Aperfeiçoamento de Pessoal de Nível Superior. Programa Nacional de Formação de Professores da Educação Básica - PARFOR. Disponível em:<http://www.CAPES.gov.br/ educacao-basica/parfor $>$ Acesso em: 29 out. $2013 \mathrm{a}$.

. PARFOR à distância. 2012. Disponível em:<http://www.CAPES. gov.br/educacao-a-distancia/parfor-a-distancia>. Acesso em: 29 out.2013.

.O que é a Universidade Aberta do Brasil? Disponível em: <http:// www.uab.CAPES.gov.br/index.php?option $=$ com_content\&view $=$ article\&id $=6$ \&Itemid=18.> Brasília: Acesso em: 30 out. 2013b.

. Programa Nacional de Formação em Administração

Pública - PNAP. Disponível em:<http://www.capes.gov.br/ educacao-a-distancia/pnap>. 2009. Acesso em: 31 maio 2014.

COSTA, C. J. Modelos de educação superior à distância e implementação da Universidade Aberta do Brasil. Revista Brasileira de Informática na Educação, Florianópolis, v. 15, n. 2, p. 9-16, 2007.

DIMAGGIO, P.; POWELL, W. The iron cage revisited: institutional isomorphism and collective rationality in organizational fields. American Sociological Review, Menasha, v. 48, n. 2, p. 147-160, 1983. doi: $10.2307 / 2095101$

EISENHARDT, K. Agency and institutional theory explanations: the case of retail sales compensation. Academy of Management Journal, Champaign, v. 31, n. 3, p. 488-511,1988. doi:10.2307/256457 
ESMAN, M. J. The elements of institution building. In: EATON, J. W. (Ed.). Institution building and development: from concepts to application. London: Sage, 1972. p. 21-339.

ESMAN, M. J.; BLAISE, H. C. Institution building research: the guiding concepts. Pittsburgh: Inter-University Research Program, 1966.

FERREIRA, M.; MILL, D. Institucionalização da educação a distância no ensino superior público brasileiro: desafios e estratégias. In: FIDALGO, F.S. et al. (Org.). Educação à distância: meios, atores e processos. Belo Horizonte: CAED-UFMG, 2013. p. 43-57.

FOUCAULT, M. A ordem do discurso. São Paulo, Loyola, 1996. Disponível em $<$ http://pt.wikipedia.org/wiki/Ordem_do_Discurso>. Acesso: 05 ago. 2014.

GREENWOOD, R.; HININGS, C. R. Understang radical organizational change: bringing together the old and the new institucionalism. 1996.

Disponível em: $<$ http://www.jstor.org/discover/10.2307/259163?uid=2129\&ui $\mathrm{d}=2 \&$ uid=70\&uid=4\&sid=21103378886911 > Acesso em: 17 fev.2014.

GUERREIRO, R.; PEREIRA, C. A.; FREZATTI, F. Evaluating management accounting change according to the institutional theory approach:a case study of a Brazilian bank. Journal of Accounting \& Organizational Change, United Kingdom, v. 2, n. 3, p. 196-228, 2006. doi:10.1108/18325910610690063

MEYER, J. W.; ROWAN, B. Institutionalized organizations: formal structure as myth and ceremony. American Journal of Sociology, Chicago, v. 83, n. 2, p. 340-363, 1977. doi:10.1086/226550

NOVAIS, S. M.; FERNANDES, A. S. A. A institucionalização do Ensino a Distância no Brasil: o caso da Graduação em Administração na Universidade Federal do Rio Grande do Norte. Revista de Ciências da Administração, Florianópolis, v. 13, n. 29, p. 173-201, 2011. doi:10.5007/2175-8077.2011v13n29p173

PORTO, G. Análise do discurso. Disponível em:<http://www.infoescola.com/ linguistica/analise-do-discurso/>. Acesso em: 26 ago.2012.

RICHARDSON, R. J. Pesquisa social, métodos e técnicas. 3. ed. São Paulo: Atlas, 1999.

SCHUTZ, A. et al. Collected papers: the problems of social reality. The Hague: Martinus Nijhoff, 1962. 
SCOTT, R. The adolescence of institutional theory. Administrative Science Quarterly, Ithaca, v. 32, n. 4, p. 493-511, 1987. doi:10.2307/2392880

SILVA, A. B. Como os gerentes aprendem. São Paulo: Saraiva, 2009.

TOLBERT, P. S.; ZUCKER, L. G. A institucionalização da teoria institucional. In: CLEGG, S. Handbook de estudos organizacionais. São Paulo: Atlas, 1999. v. 3, p. 196-219.

UAB-UNIVERSIDADE ABERTA DO BRASIL. Informações da Universidade Aberta. 2006. Disponível em: <http://www.uab.capes.gov.br/>. Acesso em: 13 maio 2014.

ZUCKER, L. G. Institutional patterns and organizations: culture and environment. Cambridge, Mass: Ballinger, 1988.

\section{Informações dos autores}

João Paulo Rodrigues do Nascimento: Mestre em Gestão em Organizações Aprendentes pela Universidade Federal da Paraíba - UFPB. Atualmente é Professor Assistente A da Universidade Federal de Pernambuco, vinculado ao departamento de Ciências Administrativas do Centro de Ciências Sociais Aplicadas, atuando na área de Técnicas e Gestão em Secretariado. Foi secretário executivo da Universidade Federal do Rio Grande do Norte, lotado na Secretaria de Educação a Distância, Natal, RN. Contato: rn.jpaulo@gmail.com

Maria das Graças Vieira: Doutora em Educação pela Universidade Federal da Paraíba - UFPB. Atualmente é Professora Adjunta IV da Universidade Federal da Paraíba, Coordenadora pro tempore de Pedagogia EaD e Professora Pesquisadora I da Universidade Aberta do Brasil - UAB/UFPB, Professora do quadro permanente do Programa de Pós-Graduação em Políticas Públicas, Gestão e Avaliação da Educação Superior da UFPB, Professora do quadro permanente do Programa de Pós-Graduação em Gestão nas Organizações Aprendentes da UFPB. Foi Professora da Universidade Federal de Pernambuco - UFPE (2009-2015). Contato: gracinhavieira@yahoo.com.br 